\title{
A PREVIDÊNCIA SOCIAL À LUZ DA TEORIA DOS DIREITOS FUNDAMENTAIS: UM DIREITO DA PERSONALIDADE
}

\section{SOCIAL SECURITY IN LIGHT OF THE THEORY OF THE FUNDAMENTAL RIGHTS: A RIGHT OF LEGAL PERSONALITY}

${ }^{1}$ Edgar Dener Rodrigues

\section{RESUMO}

Este artigo consiste em estudo realizado sobre a Teoria dos Direitos Fundamentais e o sistema de Previdência Social atualmente existente no ordenamento pátrio com objetivo de abordar a classificação dos direitos fundamentais em suas principais dimensões e respectivas características, alocando-se a previdência social dentre aqueles denominados de segunda dimensão. Isto porque, o sistema previdenciário consiste num conjunto de normas que impõe o dever de prestação material para o Estado em face de seus beneficiários quando expostos a determinados riscos sociais que submetem a pessoa a uma situação de vulnerabilidade social. A previdência social se apresenta, assim, como verdadeiro direito da personalidade, pois busca conferir meios de subsistência à pessoa humana. Nessa linha, buscou-se, a partir de pesquisa teórica e legislativa, identificar os conceitos de direito fundamental, previdência social e risco social, conjugando-se com sua previsão no ordenamento jurídico, a fim de se identificar a adequada proteção jurídica que deve ter o instituto da Previdência Social à luz da Teoria dos Direitos Fundamentais.

Palavras-chave: Direitos fundamentais, Direito da personalidade, Previdência social, Riscos sociais

\begin{abstract}
This article is a study on the theory of Fundamental Rights and the Social Security System currently existing in this country, with the objective to approach the classification of the fundamental rights in its main dimensions and characteristics, assigning Social Security among those named second dimension. This is because the pension system consists in a set of principles that imposes a duty of material rendering to the State in the face of its beneficiaries, when exposed to certain social risks, which subject the person to a situation of social vulnerability. Social Security presents itself, thus as a genuine right of legal personality, for tries to confer means of livelihood upon a human being. Along these lines it tried, from theoretical and legislative research, to identify the concepts of fundamental rights, social security and social risk, combining with its foresight in the legal system, in order to identify the appropriate legal protection that the institute of Social Security must have in light of the theory of fundamental rights.
\end{abstract}

Keywords: Fundamental rights, Right of legal personality, Social security, Social risks

\footnotetext{
${ }^{1}$ Mestrando em Ciências Jurídicas pelo Centro de Ensino Superior de Maringá - CESUMAR, Paraná (Brasil). E-mail: edgardener@gmail.com
} 


\section{INTRODUÇÃO}

A Teoria dos Direitos Fundamentais busca relacionar os direitos de proteção da pessoa humana em face do Estado, classificando-os em dimensões a partir das suas características. A doutrina majoritária relaciona três principais dimensões de direitos, as quais são associadas ao lema da Revolução Francesa: liberdade, igualdade e fraternidade. A segunda dimensão de direitos prevê o dever de prestação do Estado, cabendo-lhe agir positivamente para a promoção dos direitos sociais, dentre os quais estão incluídos os previdenciários.

A previdência social surgiu a partir de lutas dos trabalhadores que, por falta de proteção jurídica, temiam a ausência de renda para subsistência quando submetidos a situações de desemprego, doença e idade avança, dentre outros. Desse modo, a Constituição Federal trouxe em seu texto os principais riscos sociais a que o trabalhador terá proteção, cabendo ao Estado agir positivamente para criar os meios necessários à concretização desses direitos.

Os direitos da personalidade se constituem naqueles bens inerentes à pessoa humana $\mathrm{e}$ que visam sua proteção como fator primordial, alçando o Homem como elemento principal de promoção para o qual é destinada a função estatal, com o fim de assegurar sua dignidade.

O estudo demonstra que o objetivo de proteção à pessoa humana, conferido por meio do sistema previdenciário (que integra os direitos sociais e, portanto, direitos fundamentais de segunda dimensão) constituem também verdadeiros direitos da personalidade.

\section{OS DIREITOS DA PERSONALIDADE}

Estudar sobre direitos fundamentais exige tratar inicialmente sobre os direitos da personalidade, pois ambos têm como titular a pessoa humana, sendo por vezes tratados como sinônimos por diversos doutrinadores.

Tem-se assim que o titular dos direitos da personalidade é a pessoa. Para Diogo Costa Gonçalves (2008, p. 43), pessoa é conceituada como um ser psicológico, que possui consciência moral de si e da sua existência. Singulariza-se na existência de cada ser único e pessoal. Define o Homem como distinctum subsistens no sentido de que "qualquer homem que exista é, necessariamente, pessoa, será sempre pessoa, permanecera pessoa, independente do seu estado, circunstância ou aparência verdadeiros (...) só deixará de ser pessoa quando, pura e simplesmente, deixar de ser". 
Enquanto pessoa o Homem é dotado de personalidade, que é definida como "o conjunto das qualidades e relações que determinam a pessoa em si mesma e em função da participação na ordem do ser, de forma única e singular" (GONÇALVES, 2008, p. 68). Desse modo, a definição de personalidade considera o conjunto das qualidades e das relações que a pessoa possui e exerce ao longo de sua vida.

Ensina Szaniawski (2005) que a proteção da personalidade humana evoluiu consideravelmente a partir da promulgação da Declaração Universal dos Direitos do Homem, de 1789, e outras que lhe seguiram. A partir dessas declarações a pessoa humana passou a ter reconhecidos seus direitos da personalidade como sendo direitos fundamentais, mediante a proteção de sua vida, honra, liberdade, integridade física e psíquica, igualdade, intimidade, etc. Em diversas Assembleias e conferências internacionais passou-se a discutir as cláusulas de proteção da pessoa humana. Essa preocupação mundial provocou uma intensa modificação na legislação de diversos países-membros, com a finalidade de assegurar a proteção íntima das pessoas.

Bittar (1999, p. 6) considera que os direitos da personalidade são inatos à pessoa humana, cabendo ao Estado reconhece-los e positiva-los, dando a proteção própria que lhe é devida. Isso significa dizer que não representam somente aqueles estabelecidos no ordenamento positivo.

A personalidade humana consiste, assim, no conjunto de características da pessoa, sua parte mais intrínseca. A ordem jurídica tem por principal destinatário o ser humano, protegendo sua dignidade e garantindo-lhe o livre desenvolvimento da personalidade.

Szaniawski (2005), discorrendo sobre os fundamentos do direito geral de personalidade, ressalta a complexidade da personalidade humana, em especial em seus atributos. Ensina que a dignidade humana "consiste no elemento indicador da localização do ser humano no Universo, o qual, em virtude de sua natureza espiritual é dotado de dons que possibilitam a construção de determinadas tarefas de criatividade cultural, da realização de valores éticos e de se auto-edificar". Sustenta que o direito geral de personalidade, na atualidade, se opera a partir da aplicação direta e imediata dos direitos supranacionais do homem e do cidadão e da criança e do adolescente, que constituem sua fonte principal.

A dignidade da pessoa humana deve ser compreendida como um valor que transcende ao patrimonial. Adauto Tomaszewski (2006, p. 6) considera que o conceito "carrega, de forma ínsita, a reivindicação de que todos manifestem respeito ao indivíduo". Isso significa a predominância da pessoa sobre o Estado, que deve proteger e resguardar a liberdade do cidadão. 
Continua o professor ensinando que o princípio deve ser analisado sob duas óticas: "a primeira porque resguarda o indivíduo do próprio Estado" a fim de evitar novas violações deste contra a pessoa humana; a segunda porque "refere-se aos três pilares mestres dos princípios gerais de Direitos, elaborados que foram desde a época do Direito Romano: viver honestamente (honeste vivere), não lesar ninguém (alterum non laedere) e dar a cada um o que é seu (suum cuique tribuere)".

Para Szaniawski (2005) o princípio da dignidade da pessoa humana pode ser vislumbrado sob dois aspectos: por um lado, representa uma qualidade substancial do ser humano, a dignidade como sendo a expressão da essência da pessoa, e, de outro, o fundamento da ordem política e de paz social, revelando-se uma fonte de direitos.

No âmbito interno, a principal fonte do direito geral da personalidade encontra-se na Constituição, onde pode se dar por duas formas: a Constituição pode trazer expressamente a cláusula geral da personalidade humana, a exemplo da constituição alemã; ou pode tutelar a personalidade a partir de diversos princípios fundamentais, a exemplo da Constituição do Brasil de 1988, a qual traz a tutela da personalidade através do princípio mãe, da dignidade da pessoa humana e outros princípios. Esses princípios fundamentais foram um conjunto de sustentação do direito geral de personalidade e, também, informam os direitos especiais de personalidade (SZANIAWSKI, 2005, p. 120).

A Constituição Federal de 1988 não possui uma cláusula geral expressa destinada a tutelar a personalidade humana. Existe somente categorias de direitos especiais expressamente previstos. No entanto, não se pode negar a proteção aos direitos da personalidade, pois é possível observar um sistema de proteção misto. Em seu texto estabelece um rol de direitos fundamentais, dentre os quais identificam-se diversos direitos da personalidade, como vida, honra, intimidade, o que demonstrar a intensão do legislador de conferir a proteção devida a esses bens.

Vale registrar, ainda, que o direito civil positivo passou a ser lido à luz dos princípios constitucionais, deixando de tutelar tão-somente os valores patrimoniais individuais e passando a buscar a efetivação de valores existenciais e de justiça social. O direito passou a ser um sistema ético aberto, tendo como centro o ser humano, cujo fundamento do ordenamento jurídico possui por substrato a noção de dignidade (SZANIAWSKI, 2005).

Desse modo, concebe-se que a personalidade se constitui no conjunto de caracteres do próprio indivíduo, perfazendo-se na parte intrínseca da pessoa humana. Os bens valorados são 
aqueles inerentes à pessoa humana: vida, liberdade e honra, entre outros. Da proteção que se dá a esses bens primeiros do indivíduo decorrem os denominados de direitos da personalidade.

No texto constitucional verifica-se o reconhecimento explícito dos direitos previdenciários como direitos fundamentais, pois incluídos no rol dos direitos sociais previstos no art. $6^{\circ 1}$. Demais disso, tratou especificamente sobre o tema no capítulo da seguridade social (art. 194 a 202), sobre o qual será tratado nos tópicos a seguir (BRASIL, 1988).

\section{OS DIREITOS FUNDAMENTAIS E SUAS DIMENSÕES}

Desde o final do século XX a importância dos direitos fundamentais vem tomando grande destaque na sociedade, despertando o interesse de estudiosos em diversas áreas do conhecimento humano. Com isso, a doutrina passou a analisar esses direitos, extraindo algumas características principais, dentre as quais destacam-se a historicidade, a universalidade, a inalienabilidade, a imprescritibilidade, a vinculatividade e a indivisibilidade (CAMIM; FACHIN, 2015).

Assim, tem-se que os direitos fundamentais decorrem de uma construção e evolução história, identificados a partir dos anseios do homem em sua realidade social e marcados por "lutas encetadas na vida cotidiana" (FACHIN, 2015, p. 235) ao longo do tempo. Representam conquistas do homem e da sociedade em prol de garantias de uma vida digna e proteção contra abusos do Estado.

Os direitos do homem nascem, são identificados ou se destacam em determinados momentos históricos, caracterizados por lutas em defesa de novas liberdades contra velhos poderes, e nascidos de modo gradual, não todos de uma vez e nem de uma vez por todas (BOBBIO, 1992).

Paulo Gustavo Gonet Branco (2009, p. 267) denota a importância do indivíduo em face do Estado, alçando-o em patamar superior às normas positivas. Considera primeiramente a pessoa como detentora de direitos e, em segunda análise, como possuidora de deveres perante o Estado. Nesse sentido, ensina que:

\footnotetext{
${ }^{1}$ Art. $6^{\circ}$ São direitos sociais a educação, a saúde, a alimentação, o trabalho, a moradia, o lazer, a segurança, a previdência social, a proteção à maternidade e à infância, a assistência aos desamparados, na forma desta Constituição.
} 
Os direitos fundamentais assumem posição de definitivo realce na sociedade quando se inverte a tradicional relação entre Estado e indivíduo e se reconhece que o indivíduo tem, primeiro, direitos, e, depois, deveres perante o Estado, e que os direitos que o Estado tem em relação ao indivíduo se ordenam ao objetivo de melhor cuidas das necessidades dos cidadãos.

A ponderação acima bem demonstra que o Estado existe para servir ao homem, que preexiste à sua própria criação. $\mathrm{O}$ ordenamento positivo não pode ser considerado um fim em si mesmo ou criado para regular a sociedade pela vontade dos governantes. Sua finalidade precípua visa atender às necessidades vitais básicas do indivíduo e manter a paz social.

O surgimento gradual dos direitos do homem permitiu sua classificação em dimensões distintas, também chamadas de gerações de direitos. O estudo implicou a classificação em dimensões, cujas três principais são associadas ao lema da Revolução Francesa: liberdade, igualdade e fraternidade (BONAVIDES, 2007, p. 562).

Vale registrar que a terminologia utilizada para se alocar os direitos fundamentais em um determinado grupo de direitos, originados e identificados ao longo da história, por vezes é apresentada como "gerações", assim definindo períodos em que tais direitos ganharam maior relevância jurídica. Nesse sentido, Paulo Gustavo Gonet Branco (2009, p. 267) apresenta e situa a evolução dos direitos fundamentais ao longo da história em três gerações: primeira, segunda e terceira.

O vocábulo, todavia, não é o mais adequado para classificação dos direitos fundamentais, visto que a expressão geração remete à ideia de sucessão de direitos, em que os novos se sobrepõem aos anteriores numa dialética jurídica de criação e extinção. Assim exsurge a proposta de dimensão de direitos, representando o acréscimo de direitos às dimensões precedentes, com os quais coexistem harmoniosamente (FACHIN, 2015, p. 223).

Essa linha de estudo leva a uma breve análise dessas dimensões. Na primeira estão situados os direitos vinculados às liberdades. São direitos civis e políticos do cidadão, que impõem um dever de abstenção do Estado a fim de assegurar ao indivíduo sua autodeterminação. Preza primeiramente pela autonomia da vontade. Paulo Bonavides (2007, p. 563-564) classifica como aqueles oponíveis pela pessoa ao Estado, como atributos que ostentam uma subjetividade.

Os direitos de segunda dimensão, enfoque maior deste estudo, representam um dever de prestação pelo Poder Público para atender às necessidades principais de seus populares. Caracteriza-se, desse modo, a existência do Estado Social. 
A esse respeito, Zulmar Fachin (2015, p. 224) considera que os direitos de segunda dimensão "consistem no resultado das lutas travadas por uma pluralidade de atores sociais, em várias partes do mundo, contrapondo-se aos interesses da burguesia”. São conquistas decorrentes de protestos erigidos da sociedade em busca de melhor atendimento das necessidades dos menos favorecidos.

Dessas lutas firmaram-se inúmeros direitos sociais, os quais exigem uma atuação positiva do Estado para efetivação, seja de forma direta ou por mecanismos que permitam sua concretização.

Para José Afonso da Silva (2009, p. 286), a segunda dimensão dos direitos fundamentais representa o conjunto de prestações positivas a serem proporcionadas pelo Estado, direta ou indiretamente, para melhoria das condições de vida dos hipossuficientes. Consistem em direitos que tendem a realizar a igualização de situações sociais desiguais.

Os direitos fundamentais de terceira dimensão são aqueles ligados à proteção do homem enquanto espécie, não restritos a determinada região ou localidade. São direitos de proteção do gênero humano, cujo exemplo primordial se identifica nas normas de proteção ambiental. São direitos ligados à solidariedade (FACHIN, 2015, p. 225).

Ingo Sarlet (2013, p. 185) anota a importância da dupla dimensão objetiva e subjetiva dos direitos fundamentais. Registra que no Brasil, no âmbito da teoria constitucional dos direitos fundamentais, também há a noção de que não se limitam a direitos subjetivos, já que "representam decisões valorativas de natureza jurídico-objetiva da Constituição, que se projetam em todos o ordenamento jurídico". Assim, os direitos fundamentais não serão somente garantias negativas ou positivas individuais, mas um conjunto de valores objetivos básicos impostos em ordem constitucional, que servirão de norte para a ação positiva dos poderes públicos.

Em qualquer dimensão que se apresentem, esses direitos, a partir de seu reconhecimento no tex to constitucional, apresentarão um desdobramento de força objetiva, cujo efeito está associado ao fenômeno designado da "constitucionalização do Direito" (SARLET, 2015, p. 186), que traz implicações diretas na eficácia dos direitos fundamentais.

Esse reconhecimento dos direitos fundamentais impõe um conjunto de deveres para o Estado com a finalidade de zelar pela proteção da pessoa humana, não somente em face dos poderes públicos, mas também em face dos particulares. Essa atuação deve ser dar pela elaboração de normas negativas que proíbam atos que causem prejuízo ao cidadão, como 
também a edição de normas positivas, que especifiquem uma obrigação de fazer pelo Poder Público, de modo a garantir à pessoa o exercício de seus direitos da personalidade.

Nessa linha, as normas previdenciárias, como se verá a seguir, representam um sistema de regras impositivas, de ordem positiva e negativa, com o fito de proporcionar à pessoa meios de manutenção de sua subsistência quando for submetida à determinados situações que lhe impeçam o exercício da atividade laboral.

\subsection{Características}

Para identificação dos direitos fundamentais se faz necessária uma análise de suas características principais, que os distinguem dos demais direitos e elevando-os a um maior grau de importância.

Zulmar Fachin (2015, p. 235-241) identifica como caracteres principais a universalidade, inalienabilidade, imprescritibilidade, indivisibilidade, inexauribilidade, positividade, transindividualidade, complementariedade, aplicabilidade imediata e vinculatividade.

São universais porque aplicáveis em todos os lugares e a todas as pessoas; inalienáveis, pois são intransferíveis e não possuem conteúdo patrimonial; imprescritíveis por não se perderem pelo seu não uso; indivisíveis, assim compreendidos por não serem dissociados de outros direitos sociais, econômicos e culturais; inexauríveis, cujo rol previsto na Constituição Federal é meramente exemplificativo; transindividuais, pelo que pertencem a todas as pessoas indistintamente; positivados, assim considerados aqueles incorporados ao ordenamento jurídico do Estado, apesar se reconhecer a existência de direitos fundamentais independentemente de terem sido admitidos pelo Estado em suas normas.

A respeito, ainda, a característica da complementariedade decorre da interdependência existente entre os direitos fundamentais, que não se excluem, mas se complementam. A aplicabilidade imediata consiste na possibilidade de sua imposição desde logo, independente da elaboração de leis ou regulamentos. Por fim, a vinculatividade impõe ao Estado e aos particulares o dever de respeito e observância dos direitos fundamentais em suas relações.

Gomes Canotilho (1993, p. 537-538) também anota a dupla vinculação do Estado aos direitos fundamentais, numa perspectiva negativa e outra positiva. Como atos negativos considera o direito à liberdade de pensamento, sem impedimentos pelos entes públicos; direito à não-intervenção em situações jurídico-subtectivas; e o direito à não eliminação da propriedade 
privada. A perspectiva positiva representa as imposições normativas que geram direito ao indivíduo a uma prestação positiva do Estado.

\section{A PREVIDÊNCIA SOCIAL NO BRASIL}

\subsection{Origem Da Proteção Previdenciária}

A previdência social surgiu a partir dos problemas agravados com a Revolução Industrial, com origem germânica (MORAES, 2007, p. 2102). Em 1983, na Alemanha, foi criado o seguro-doença, obrigatório para os trabalhadores da indústria, o qual foi seguido da criação do seguro contra acidade de trabalho em 1884 e seguro de invalidez e velhice em 1889 (TAVARES, 2006, p. 38).

Os diversos problemas sociais surgidos a partir Revolução Industrial impulsionaram a criação dos sistemas previdenciários. Nessa época, o indivíduo passou a trabalhar em linhas de produção em massa, como empregado, sendo sobrecarregado por tarefas repetitivas, que culminavam em doenças ocupacionais. Além disto, havia a insegurança pela falta de renda para subsistência quando não mais pudesse trabalhar, fosse em razão de doença, desemprego ou velhice.

O sistema previdenciário se expandiu pelo mundo, sendo previsto constitucionalmente pela primeira vez no México, em 1917, e posteriormente na constituição alemã de Weimar, em 1919 (TAVARES, 2006, p. 39).

No Brasil, a Constituição de $1891^{2}$ foi a primeira a prever diretamente um benefício previdenciário, ao assegurar a aposentadoria por invalidez aos funcionários públicos que se tornassem inválidos a serviço da nação (BRASIL, 1891).

Posteriormente foram criados outros direitos na legislação infraconstitucional, prevalecendo, entretanto, que a inauguração do sistema previdenciário se deu com a Lei Eloy Chaves, em 1923, que determinou a criação das caixas de aposentadorias e pensões para os ferroviários (AMADO, 2015, p. 87).

Nesta época, os ferroviários eram numerosos e formavam uma categoria própria de trabalhadores. As caixas eram administradas pelas próprias empresas, sendo que o poder público apenas regulamentava e supervisionava a atividade.

\footnotetext{
${ }^{2}$ Art 75 - A aposentadoria só poderá ser dada aos funcionários públicos em caso de invalidez no serviço da Nação.
} 
A Constituição de 1934 estabeleceu a tríplice forma de custeio, abrangendo o ente público, o trabalhar e o empregador. A Carta de 1937, que criou o Estado Novo, empregou a expressão "seguro social”. Após, em 1946, a Constituição previu a nomenclatura "previdência social, elencando como riscos sociais a doença, velhice, invalidez e a morte (TAVARES, 2006, p. 43).

A Constituição Federal de 1988 previu expressamente a previdência social como direito social $\left(\right.$ art. $\left.6^{\circ}\right)$. Estabeleceu seus princípios juntamente com o sistema da seguridade social, a partir do art. 194, que prevê além da previdência social os direitos à saúde e à assistência social.

\subsection{A Seguridade Social E Suas Vertentes Constitucionais}

A seguridade social é tema que integra o grupo dos direitos sociais enquanto dimensão de direitos fundamentais do homem, compreendendo os direitos relativos à saúde, à previdência e à assistência social.

Na Constituição Federal de 1988 a seguridade foi subdividida em normas sobre saúde, previdência e assistencial social, regendo-se pelos princípios da universalidade, da cobertura e do atendimento, da igualdade ou equivalência dos benefícios, da unidade de organização pelo Poder Público e pela solidariedade financeira, uma vez que é financiada por toda a sociedade (MORAES, 2007, p. 2013).

Seu conceito pode ser extraído diretamente do texto constitucional, no art. 194, que estabelece que seguridade social compreende um conjunto integrado de ações de iniciativa dos Poderes Públicos e da sociedade, destinadas a assegurar os direitos relativos à saúde, à previdência e à assistência social.

Não por menos, a ideia de seguridade tem por finalidade prevenir o homem contra os riscos sociais a que está sujeito e que, em determinadas situações, superam suas próprias forças e previsões. Constitui um seguro de plano social, com vista a garantir um atendimento mínimo ao cidadão quando surpreendido por determinados deficiências.

De efeito, com o crescimento progressivo do Estado Social, o Poder Público se viu obrigado a assumir gradativamente a responsabilidade pela efetivação das prestações positivas econômicas e sociais, impondo-se a criação de um conjunto normativo que permitisse a concretização desses direitos sociais (AMADO, 2015, p. 26). 
Desse modo, optou o constituinte por incluir dente o rol de proteções fundamentais da seguridade a proteção à saúde, a assistência social e a previdência social.

$\mathrm{O}$ direito à saúde tem por norte principal a proteção da vida e garantia de um atendimento digno. Assegura a Constituição Federal de 1988 que a saúde é direito de todos e dever do Estado, garantido mediante políticas sociais e econômicas que visem à redução do risco de doença e de outros agravos e ao acesso universal e igualitário às ações e serviços para sua promoção, proteção e recuperação (BRASIL, 1988, art. 196).

Tal norma prevê uma dupla imputação ao Estado, com uma prestação positiva e outra negativa. Apresenta-se um dever de abstenção, no sentido de não cometer ou permitir atos que comprometam a saúde de seus cidadãos e impõe o dever de atuar positivamente na prevenção e recuperação de moléstias que afetem a saúde da pessoa.

A assistência social, por sua vez, será prestada a quem dela necessitar, independente de contribuição, consoante previsão constitucional (BRASIL, 1988, art. 293). Consiste na face universalizante da seguridade social, conforme assevera José Afonso da Silva (2009, p. 310311). Terá direito todo aquele que atender aos requisitos previstos em lei, independente de prévia contribuição.

A previdência social é o sistema que representa propriamente um seguro social. José Afonso ensina que "a previdência tende a ultrapassar a mera concepção de instituição do Estado providência (welfare state), sem, no entanto, assumir características socializantes, até porque estas dependem mais do regime econômico do que do papel social” (SILVA, 2009, p. 310).

De forma mais precisa, o sistema previdenciário busca amparar o indivíduo que se qualifique como segurado, prestando-lhe meios de subsistência quando acometido por doença, invalidez, morte e idade avançada, situações estas qualificadas como riscos sociais. Isto porque, a impossibilidade de manutenção da subsistência, pessoal ou familiar, pode agravar situações de miserabilidade, ferindo diretamente a dignidade da pessoa humana.

\subsection{Princípios Da Seguridade}

Da análise do parágrafo único do art. 194 da Constituição Federal de 1988 se extraem os princípios que regem a seguridade social, e, assim, também a previdência social. Para o momento, serão analisados aqueles de maior destaque e que coadunam com a demonstração de ser a previdência social um direito fundamental de segunda dimensão. 
Nesse ponto, Marcos Correia (2013, p. 1904) anota que os princípios da seguridade social previstos pela Constituição de 1988 são: a) princípio da solidariedade, b) princípio da universalidade objetiva e subjetiva, c) princípio da uniformidade, d) princípio da seletividade, e) princípio da irredutibilidade dos benefícios, f) princípio da equidade da participação no custeio, g) princípio na diversidade da fonte de custeio, h) princípio do caráter descentralizado e democrático da gestão.

Quando à universalidade, aparece como postulado de todo e qualquer sistema de seguridade social, em que o programa deve buscar cobrir o maior número de pessoas possível, observadas as mais diversas situações possível de cobertura. Trata-se de um princípio amplo, que deve ser aplicado de forma a dar a maior efetividade desejada ao sistema previdenciário.

O princípio da seletividade é analisado a partir da limitação dos recursos orçamentários do Estado, vez que é seria praticamente impossível cobrir tudo e todos os riscos sociais. Assim, busca-se selecionar o maior número possível situações a serem cobertas quanto a previsão orçamentaria permita alcança-las.

A uniformidade do tratamento se apresenta como norma de proteção de não discriminação, visto que impõe atendimento igualitário às populações urbanos e rurais, situação que também impôs ajustes na legislação que diz respeito ao custeio e manutenção dos benefícios previdenciários. A equidade da participação no custeio e a diversidade da fonte de custeio representam regras impositivas ao Estado para a criação de mecanismos de reforço do sistema contributivo para garantir o atendimento universal e uniforme a todos que necessitarem da proteção previdenciária.

Sem embargos, a previdência social tem por essência proteger a pessoa contra os chamados riscos sociais, tema que será analisado a seguir.

\subsection{Riscos Sociais}

O sistema previdenciário é idealizado de forma a proteger o cidadão dos chamados riscos sociais, que representam situações excepcionais que retiram do trabalhador sua capacidade laboral, impossibilitando-o de auferir renda para seu sustento. Sua principal função é evitar que a pessoa fique em situação de miserabilidade ao ter que se desfazer de seus bens para cumprir compromissos por não possuir qualquer rendimento. 
A Previdência Social é tradicionalmente definida como um seguro sui generis, pois de filiação compulsória para os regimes básicos, coletivo, contributivo e de organização estatal, que ampara seus beneficiários contra riscos sociais. Consiste numa técnica protetiva mais evoluída que os antigos seguros sociais e com maior abrangência (IBRAHIM, 2014, p. 27).

No texto constitucional foram previstos três regimes de previdência pública, que seguem os mesmos princípios gerais: o regime próprio de previdência, aplicável aos servidores públicos em geral, previsto nos artigos 39 e 40; o regime próprio dos militares, regulamentado na legislação infraconstitucional ${ }^{3}$ mediante ressalva trazida no art. $142, \S 3^{\circ}$, X; e o grande regime geral de previdência social, estabelecido nos artigos 201 e 202, para atendimento de todos os demais trabalhadores em geral.

A norma do art. 194 da Constituição Federal de 1988 traz os objetivos e princípios que regem a seguridade social e, por consequência, aplicáveis também à previdência social. Merecem destaque os incisos I e II, pelos quais o sistema previdenciário deverá observar a universalidade de cobertura e atendimento e a uniformidade e equivalência dos benefícios.

A universalidade é característica dos direitos humanos e significa que o regime deverá atender a todas às pessoas que dele necessitem, da forma mais abrangente possível (TAVARES, 2006, p. 02). Contudo, em função das limitações orçamentárias, a Previdência atenderá a determinadas categorias de segurados que contribuírem para o sistema. A uniformidade e equivalência dos benefícios busca dar tratamento igualitário às populações urbanas e rurais a fim de superar diferenças históricas de tratamento que existiam no ordenamento jurídico brasileiro.

A ideia de risco social protegido pelo sistema abrange desde adversidades da vida a que qualquer pessoa está submetida, como doença ou acidente, ou outros eventos previsíveis, como idade avançada e maternidade (IBRAHIM, 2014, p. 28). Os principais riscos a serem cobertos pelos regimes previdenciários podem ser extraídos do art. 201 do texto constitucional, que, em que pese ser específico do regime geral previdenciário, também são repetidos para os outros regimes, em maior ou menor amplitude.

Nesse ponto, os principais eventos previstos para o regime geral previdenciário são:

I - cobertura dos eventos de doença, invalidez, morte e idade avançada;

${ }^{3}$ Leis $n^{\circ} 6.880 / 1980$ e 3.765/1960. 
Primeiro inciso do artigo 201, estabelece proteção para as situações de maior risco social e que mais afetam os indivíduos, causando impedimentos para obtenção de renda para o sustento.

O evento doença também é protegido na área da saúde, mas por outra ótica. Naquela, busca-se a prevenção da doença ou a sua cura. No sistema previdenciário, a proteção é mediante

o pagamento de quantia em dinheiro, calculada a partir de critérios legais, para garantir a subsistência do trabalhador. Será devido o benefício denominado auxílio-doença, cabível quando se tratar de incapacidade temporária.

A proteção contra invalidez assegura um rendimento mensal de forma vitalícia, assim como a previsão para idade avançada. São situações em que o beneficiário já não tem mais condições de trabalhar, ou sua capacidade está reduzida. Para tanto, previu o legislador ordinário o pagamento do benefício de aposentadoria por invalidez, para os casos de incapacidade total, e do benefício de auxílio-acidente, quando a incapacidade for parcial.

A cobertura do evento morte consiste em uma prestação a ser destinada aos dependentes do segurado que falecer, para garantir as condições mínimas de sustento.

II - proteção à maternidade, especialmente à gestante;

Consiste numa renda mensal a ser paga entre o último e os primeiros meses após o parto, garantindo-se que a mãe permaneça mais tempo com seu filho nos primeiros dias de vida (BRASIL, 1991, art. 75).

\section{III - proteção ao trabalhador em situação de desemprego involuntário;}

Em que pese ter sido alocado pelo legislador como risco social a ser protegido pela previdência, para proteção de desemprego involuntário foi instituído o seguro-desemprego (BRASIL, 1990), cujos recursos financeiros são pagos pelo Ministério do Trabalho e Emprego. Desta feita, é não considerado como benefício previdenciário, mas de natureza assistencial (AMADO, 2015, p. 67).

IV - salário-família e auxílio-reclusão para os dependentes dos segurados de baixa renda;

O salário-família é destinado ao trabalhador de baixa renda, como forma de ampliar 
os seus ganhos se atendidos os requisitos. Terá direito de acordo com a quantidade de filhos de até 14 anos de idade (BRASIL, 1991, art. 65).

O auxílio-reclusão também é um benefício destinado aos dependentes do segurado, assim como previsto para o evento morte (BRASIL, 1991, art. 80). Uma vez submetido à prisão, não terá como auferir renda para sustendo da família, justificando a concessão do benefício.

Esses são os principais eventos eleitos pelo legislador como riscos sociais a que os indivíduos estão sujeitos. Nada impede, todavia, que outras situações sejam protegidas, visto que o sistema previdenciário deve ser pautado pelo princípio da universalidade da cobertura e do atendimento, expressamente previsto no art. 194, I da Constituição Federal.

\section{CONSIDERAÇÕES FINAIS}

Os direitos da personalidade são os inerentes à pessoa humana, que asseguram ao homem a garantia de uma vida digna e o atendimento às necessidades vitais básicas de sobrevivência. Os direitos fundamentais, por sua vez, são aqueles positivados pelo Estado em seu texto constitucional com a finalidade de conferir tratamento especial melhor proteção aos indivíduos.

A Teoria dos Direitos Fundamentais classifica-os em grupos, assim divididos a partir de características próprias, que recebem a designação de dimensões ou gerações de direitos, cujas três principais consistem em: deveres de abstenção (primeira dimensão); deveres de prestação (segunda dimensão); deveres de proteção (terceira dimensão).

O surgimento desses direitos positivados é proveniente de lutas sociais travadas pelo povo contra o Estado, ao longo da história, objetivando o reconhecimento da sua existência e a necessidade de sua proteção.

Nessa linha, os inconvenientes criados a partir da revolução industrial geraram a necessidade de criação de normas de proteção dos trabalhadores, não só no âmbito trabalhista, mas em questões que margeiam a relação de trabalho, a exemplo impossibilidade de exercer atividade remunerada em função de doenças, acidentes ou idade avançada. Surgem assim as primeiras formas de proteção previdenciária, a partir da criação de sistemas de auxílio-doença e seguro-acidente.

Com efeito, a previdência social consiste num direito fundamental do indivíduo, conceituada como espécie de seguro sui generis, de filiação compulsória, que visa proteção 
contra os denominados riscos sociais. Tais riscos representam adversidades da vida humana a que as pessoas estão sujeitas, abrangendo eventos como morte, doença, idade avançada e maternidade, que impedem que o trabalhador obtenha renda em sua atividade laboral, colocando-o, juntamente com sua família, em situação de vulnerabilidade social.

Não por menos, o legislador previu expressamente a previdência social como um direito social, objetivando impor ao Estado o dever de prestar a assistência material necessária ao indivíduo que se encontre em determinados riscos sociais. Elencou-se também os principais eventos a serem cobertos pelo sistema, buscando-se dar maior amplitude ao regime previdenciário.

Denota-se que as normas que regem o sistema previdenciário criam um dever de prestação social para o Estado em face de seus cidadãos, consistente no pagamento de determinadas quantias monetárias para aqueles que se enquadrarem como beneficiários, para garantia do sustento e manutenção mínima da dignidade da pessoa humana.

Desse modo, a Previdência Social está incluída dentre os direitos fundamentais de segunda dimensão, cuja finalidade principal busca a concretização dos direitos sociais básicos, com vista a alcançar de modo formal e material um Estado Social de Direito. Outrossim, a essência da proteção previdência em face do ser humano configura também um direito de personalidade, o qual jamais poderá ser afastado em prejuízo do seu titular, ainda que ocorra alteração do texto legal ou exclusão da previdência do rol dos direitos fundamentais.

\section{REFERÊNCIAS}

AMADO, Frederico. Curso de Direito e Processo Previdenciário. Salvador: Juspodivm, 2015.

BITTAR, Carlos Alberto. Os Direitos da Personalidade. Rio de Janeiro: Editora Forense Universitária, 1999.

BOBBIO, Norberto. A Era dos Direitos. Trad. Nelson Coutinho. Rio de Janeiro: 1992.

BONAVIDES, Paulo. Curso de Direito Constitucional. São Paulo: Malheiros, 2007.

BRANCO, Paulo Gustavo Gonet. MENDES, Gilmar Ferreira. COELHO, Inocêncio Mártires. Curso de Direito Constitucional. São Paulo: Saraiva, 2009.

BRASIL. Constituição da República dos Estados Unidos do Brasil. Diário Oficial [da] República Federativa do Brasil. Brasília, DF, 24 fev. 1891. 
Constituição Federal. Diário Oficial [da] República Federativa do Brasil. Brasília, $\overline{\mathrm{DF}, 05}$ dez. 1988.

Lei $\mathrm{n}^{\text {0 }}$ 7.998, de 11 de janeiro de 1990. Dispõe sobre os Planos de Benefícios da Previdência Social e dá outras providências. Diário Oficial [da] República Federativa do Brasil. Brasília, DF, 12 jan. 1990.

Lei $n^{\circ} 8.213$, de 24 de julho de 1991. Dispõe sobre os Planos de Benefícios da Previdência Social e dá outras providências. Diário Oficial [da] República Federativa do Brasil. Brasília, DF, 25 jul. 1991.

CAMIN, Gustavo V. FACHIN, Zulmar. Teoria dos Direitos Fundamentais: Primeiras Reflexões. Revista Jurídica Cesumar. Maringá, Vol. 15, n. 1, p. 41-54, jan/jun. 2015.

CANotilho, J. J. Gomes. Direito Constitucional e Teoria da Constituição. Coimbra: Almedina, 1993.

CORREIA, Marcus O. G. Comentários ao artigo 194. In: CANOTILHO, J. J. Gomes; MENDES, Gilmar F.; SARLET, Ingo W; STRECK, Lenio L. (Coords). Comentários à Constituição do Brasil. São Paulo: Saraiva/Almedina, 2013.

FACHIN, Zulmar. Curso de Direito Constitucional. Rio de Janeiro: Forense, 2015.

GONÇAlveS, Diogo Costa. Pessoa e Direitos da Personalidade. Fundamentação Ontológica da Tutela. Coimbra: Editora Almedina, 2008.

IBRAHIM, Fábio Zambitte. Curso de Direito Previdenciário. 19. ed. Rio de Janeiro: Impetus, 2014.

MORAES, Alexandre de. Constituição do Brasil Interpretada e Legislação Constitucional. São Paulo: Atlas, 2007.

ROMASZEWSKI, Adauto de Almeida. Lições Fundamentais de Direito. Direitos da Personalidade. Vol. I. Londrina: Biblioteca Central da Universidade Estadual de Londrina. 2006.

SARLET, Ingo W. Notas Introdutórias ao Sistema Constitucional de Direitos e Deveres Fundamentais. In: CANOTILHO, J. J. Gomes; MENDES, Gilmar F.; ; STRECK, Lenio

L. (Coords). Comentários à Constituição do Brasil. São Paulo: Saraiva/Almedina, 2013.

SILVA, José Afonso da. Curso de Direito Constitucional. São Paulo: Malheiros, 2009.

SZANIAWSKI, Elimar. Direitos de Personalidade e sua Tutela. $2^{a}$ ed., São Paulo: Revistas dos Tribunais, 2005.

TAVARES, Marcelo Leonardo. Direito Previdenciário. Rio de Janeiro: Lúmen Juris, 2006. 